\title{
Development of Multiaxial Creep Testing Machine for Miniature Specimen
}

\author{
Noritake Hiyoshi ${ }^{1,1}$, Takamoto Itoh $^{2}$, Masao Sakane ${ }^{2}$, Takafumi Tsurui ${ }^{3}$ and \\ Masaaki Tsurui ${ }^{3}$ \\ ${ }^{1}$ University of Fukui, Division of Engineering, 3-9-1 Bunkyo Fukui-shi Fukui 910- \\ 8507, Japan \\ ${ }^{2}$ Ritsumeikan University, Department of Mechanical Engineering, 1-1-1 Noji-higashi \\ Kusatsu-shi Shiga 525-8577, Japan \\ ${ }^{3}$ Kobe Material Testing Laboratory Co., Ltd, 47-13 Niijima Harima-cho Hyogo 675- \\ 0155, Japan
}

\begin{abstract}
High temperature components such as boiler tube and jet engine turbine blade undergo multiaxial creep damage. Although multiaxial creep testing investigation is required for safety high temperature components designing, there are few commercial testing machines which can conduct multiaxial loading at high temperature. A new miniature cruciform specimen, which has a $5 \mathrm{~mm}$ square size plane stress gauge part, was designed by using FE analysis. A biaxial tensile loading creep testing machine was also designed to conduct multiaxial creep testing. The testing machine has $2 \mathrm{kN}$ loading capacity and $1 \mathrm{~kW}$ furnace. We had also developed a non-contact displacement measuring method for the miniature specimen. This method uses conventional optical camera to get the surface observation photograph. Chasing the trace of the target mark painted at surface of the specimen, we can get the displacement of the specimen. The calculated strain value obtained from the non-contact displacement measuring method corresponds with the strain gauge value at room temperature. By using the multiaxial creep testing machine and the non-contact observation system, we can investigate not only deformation of the testing specimen but also surface conditions of materials during the creep testing.
\end{abstract}

\section{Introduction}

Structural components such as thermal power plant pipe and turbine blade of airplane engine undergo not only uniaxial loading but also multiaxial loading at high temperature. Although studies of multiaxial loading at high temperature are essential for commercial product development and designing, there is little experimental research on multiaxial creep.

\footnotetext{
$1 \quad$ Corresponding author: hiyoshin@u-fukui.ac.jp
} 
There are several loading type of multiaxial creep testing methods. One is a conventional uniaxial tensile loading using a notched bar specimen. Another testing method is applying combined tension-torsion loadings to a hollow cylinder specimen [1-3]. The other testing method is applying biaxial tensile loadings to a cruciform specimen. Since the biaxial tensile loading test can conduct wide range of multiaxial stress conditions, multiaxial research with the cruciform specimen have been conducted by authors [4-5]. Although the cruciform specimen has some merit for multiaxial testing, present cruciform specimen has $190 \mathrm{~mm}$ x $190 \mathrm{~mm}$ size. As testing specimen size miniaturization will enable to conduct mechanical testing with a small amount of materials which is sampled from the actual structural components such as thermal power plant pipe and turbine blade of airplane engine, a miniature cruciform testing specimen and testing machine are required for creep testing. Since there is no commercial miniature multiaxial creep testing machine for cruciform specimen, we have developed a biaxial tensile loading testing machine. A small size cruciform specimen was designed for high temperature multiaxial loading by using finite elements analysis.

The specimen has $5 \mathrm{~mm}$ x $5 \mathrm{~mm}$ size square gauge area which is designed as stress distribution of the area to be constant. The specimen has four loading arms for tensile loading. Changing the applied load value to the loading arm, various principal stress ratio $\lambda$, which is used for expressing a stress multiaxiality, can be conduct in the range from $\lambda=0$ to $\lambda=1$.

This study had also developed a non-contact displacement measuring method which uses a conventional optical observation apparatus. The method can trace a movement path of some small target marks painted on the gauge area and calculates the strain of the specimen. The strain value obtained from the non-contact displacement measuring method corresponds with the strain gauge value and linear variable differential transformer value at room temperature and high temperature, respectively.

\section{Multiaxial creep testing method}

\subsection{Miniature cruciform specimen}

Figure 1 shows shape and dimensions of a newly designed miniature cruciform specimen. The specimen has $5 \mathrm{~mm}$ x $5 \mathrm{~mm}$ square size and $1 \mathrm{~mm}$ thickness in center gauge part and $50 \mathrm{~mm} \times 50 \mathrm{~mm}$ in total width. Figure 2 is a photograph of the machined cruciform specimen. Four long-slitted arms are attached to the center gauge part to tensile loading.

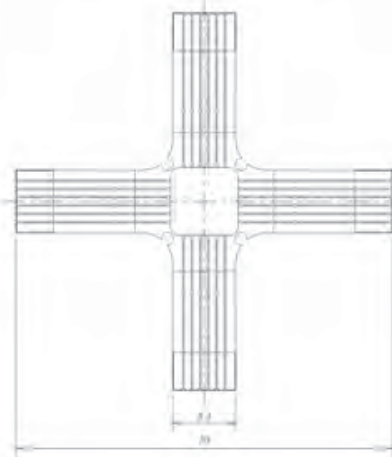

Fig. 1. Shape and dimensions of miniature cruciform specimen.

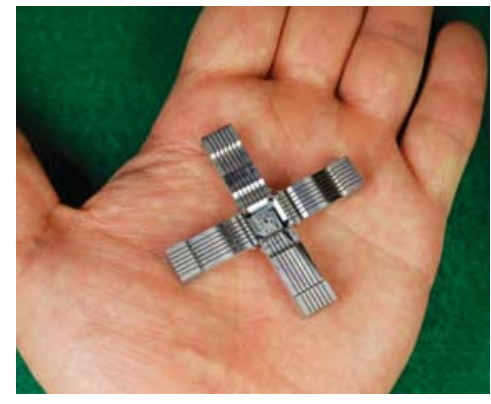

Fig. 2. General view photograph of miniature cruciform specimen. 
Figure 3 shows finite elements method (FEM) mesh for stress analysis of the cruciform specimen. Considering symmetry of the specimen shape and loading conditions, one-eighth of analysis object was meshed for FE calculation. The mesh has 25760 tetrahedron type elements and 45096 nodes. FE elastic-creep analysis under biaxial with $P_{\mathrm{x}}=P_{\mathrm{y}}=2 \mathrm{kN}$ condition was conducted by using commercial software MSC Marc/Mentat 2010. In this study, a principal stress ratio $\lambda$ is used for expressing the stress multiaxiality and is calculated as follows,

$$
\lambda=\frac{\sigma_{2}}{\sigma_{1}}
$$

where $\sigma_{1}$ and $\sigma_{2}$ are maximum principal stress and minimum principal stress, respectively. According to this definition, equi-biaxial tensile loading test is expressed as $\lambda=1$.

Figure 4 shows Mises equivalent stress distribution at immediately after tensile loading. The equivalent stress of the miniature cruciform specimen is $200 \mathrm{MPa}$ for $2 \mathrm{kN}$ tensile loading. Figure 5 depicts stress distribution results of center gauge part at immediately after tensile loading. Mises equivalent stress varies within a $\pm 5 \%$ at from center of the gauge part to $2.5 \mathrm{~mm}$. Since $\sigma_{z}$ stress component is zero at center gauge part, plane stress condition is achieved with this shape and dimensions.

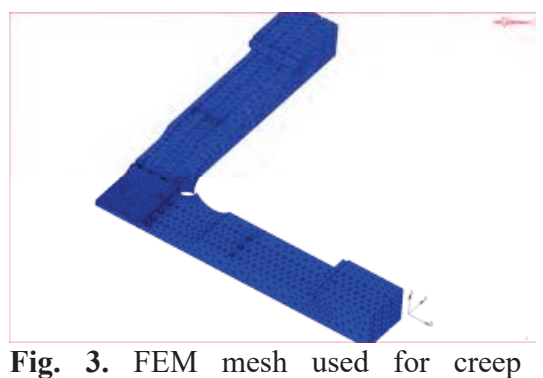
analysis.

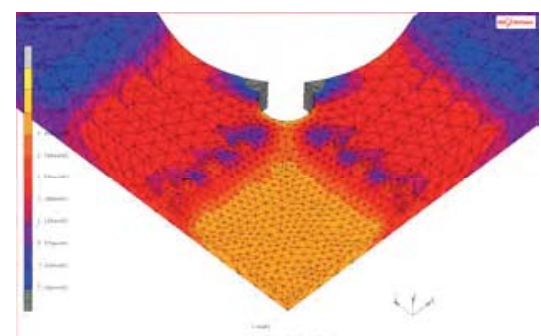

Fig. 4. Mises equivalent stress distribution of the designed specimen at $2 \mathrm{kN}$ and $\lambda=1$.

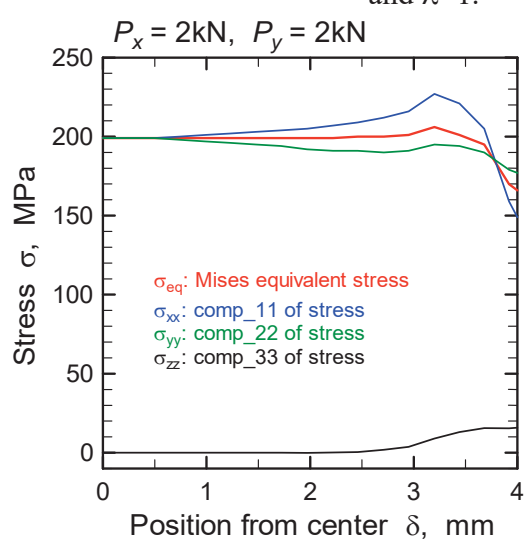

Fig. 5. Stress distribution at center gauge part of the cruciform specimen.

\subsection{Multiaxial creep testing machine}

Figure 6 shows schematic figure of a biaxial creep testing machine. The base size is $600 \mathrm{~mm} \times 600 \mathrm{~mm}$ and total height is $1000 \mathrm{~mm}$. Tensile loading is loaded by dead-weight arranged at $\mathrm{X}$-axis direction and $\mathrm{Y}$-axis direction of the specimen ((iv) in Fig. 6 and Figure 7 (a)). Load of the dead-weight for axial loading is increased by a factor of five with lever mechanism ((ii) in Fig. 6). The maximum loading capacity of the machine is $2 \mathrm{kN}$. The specimen is 
heated with $1 \mathrm{~kW}$ electric resistance furnace and the maximum temperature of the furnace is $1123 \mathrm{~K}$ ((i) in Fig. 6 and Figure 7 (b)).

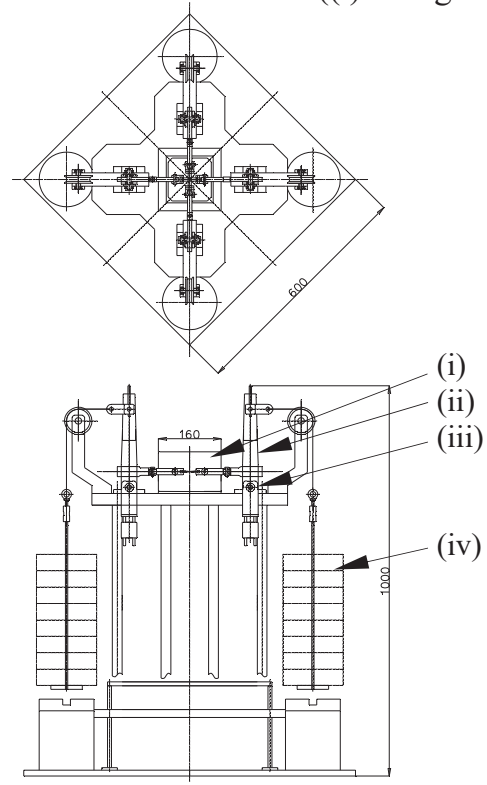

(i) Specimen in furnace (ii) Lever

(iii) Fulcrum of lever (iv) Dead weight

Fig. 6. Schematic figure of developed testing machine.

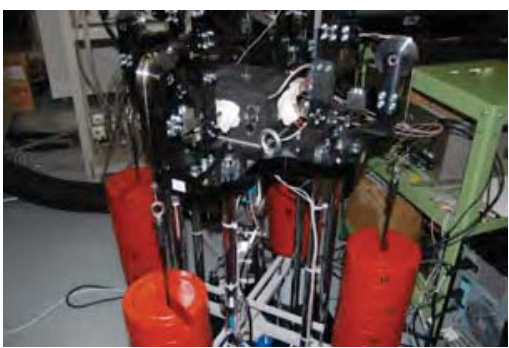

(a) Tensile loading method

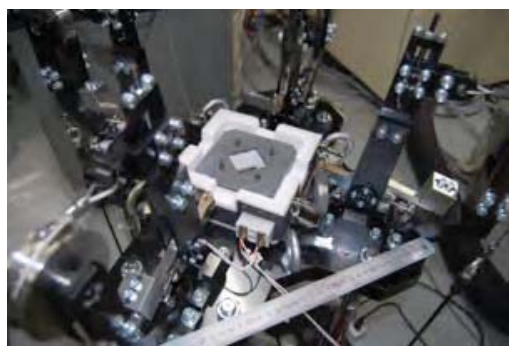

(b) Furnace

Fig. 7. General view photograph of testing machine.

\subsection{Non-contact displacement measuring method}

A testing specimen size miniaturization has both merit and demerit for materials testing. Strain measuring during creep testing is required for creep deformation understanding. Because of strain gauge method is not used for creep testing due to high temperature environment, mechanical extensometer is usually used for creep testing. Since the newly designed miniature cruciform specimen has a too small gauge part area to attach the mechanical extensometer, we confirmed the adaptation of a non-contact displacement measuring method.

The non-contact displacement measuring method uses static pictures of the testing specimen which is taken during creep testing. A conventional industrial CCD camera, which have spec of $10 \mathrm{M}$ pixels, is located at under the furnace which has $40 \mathrm{~mm} \times 40 \mathrm{~mm}$ viewing windows made of heat resistant quartz glass and observes a small circle shaped marks painted on the gauge part of the specimen. Conversion from the movement path of observed circle shaped marks to numerical value, strain of the gauge part can be calculated. By using this non-contact displacement measuring method, both $\mathrm{X}$-axis and $\mathrm{Y}$-axis strain of the miniature cruciform specimen can be measured.

We had conducted static tensile testing of aluminium alloys at room temperature and displacement of the testing specimen are measured by both conventional strain gauge method and the non-contact displacement measuring method proposed in this study. Figure 8 shows strains during tensile testing. Calculated strain obtained by the non-contact displacement measuring method (circle mark) corresponds with the strain gauge value until $2 \%$ strain and can investigate large strain which conventional strain gauge cannot measures at both tensile direction (Y-axis) and perpendicular direction to the specimen axis ( $\mathrm{X}$-axis). 
We had also conducted static tensile testing of type 304 stainless steel at $573 \mathrm{~K}$ and displacement of the testing specimen are measured by both conventional LVDT (Linear Variable Differential Transformer) method and the non-contact displacement measuring method. Figure 9 shows comparison results of the calculated strain with measured strain by LVDT. Approximate line in Fig. 9 indicate that non-contact displacement measuring method is also useful for mechanical testing at high temperatures. We had confirmed in advance that the print ink for target mark painting never disappear even though at high temperature environment until 1000 hours.

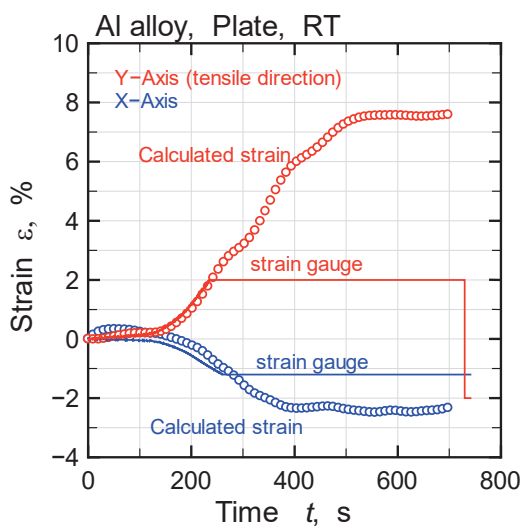

Fig. 8. Calculated strain with noncontact measuring method for aluminium alloy at room temperature.

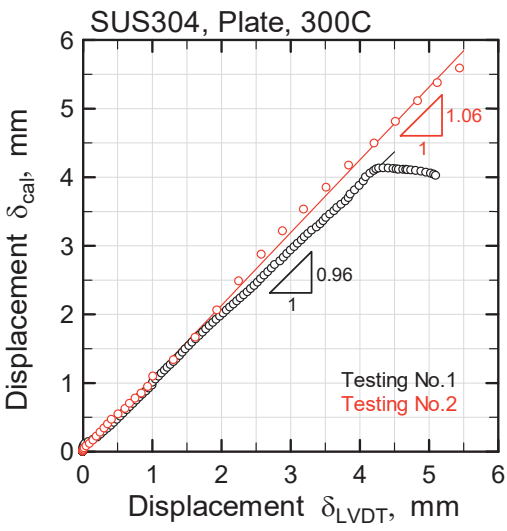

Fig. 9. Comparison of non-contact measured strain with mechanical strain measured by LVDT at high temperature.

\section{Creep testing results}

\subsection{Uniaxial creep testing}

Uniaxial creep testing of type 304 stainless steel with uniaxial plate type specimen was conducted at $923 \mathrm{~K}$ to confirm the ability of the developed testing machine. Figure 10 (a) and (b) shows observed photograph of testing specimen at 0 hour and just before rupture, respectively. Two circle shaped marks colored in black painted at both side of center gauge part are target mark for non-contact displacement measuring. Chasing the trace of the target mark, we can get the displacement of the specimen and can calculate the nominal strain of the specimen. In Fig. 10 (b), necking deformation at just before rupture and many cracks on the surface of the specimen are observed clearly. These results imply that the non-contact displacement measuring method also can investigate in-site creep deformation analysis.

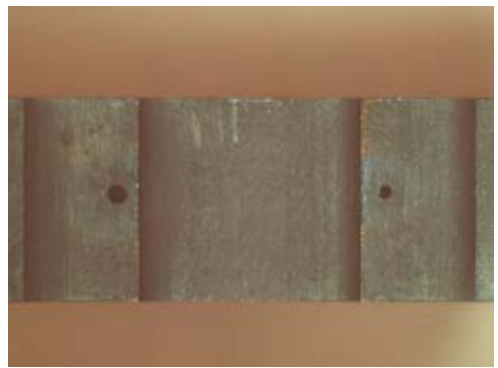

(a) At the start of testing

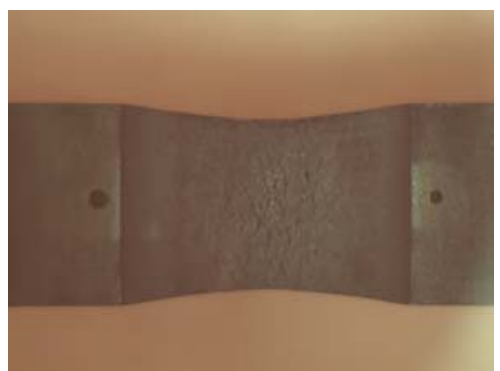

(b) Just before rupture

Fig. 10. Observed photograph of the uniaxial plate type specimen at $923 \mathrm{~K}$. 
Figure 11 is time-calculated strain curve for uniaxial testing at $923 \mathrm{~K}$ and $208 \mathrm{MPa}$. Transient creep, steady state creep, accelerating creep region in the Fig. 11 indicates that the non-contact displacement measuring method can draw creep curve.

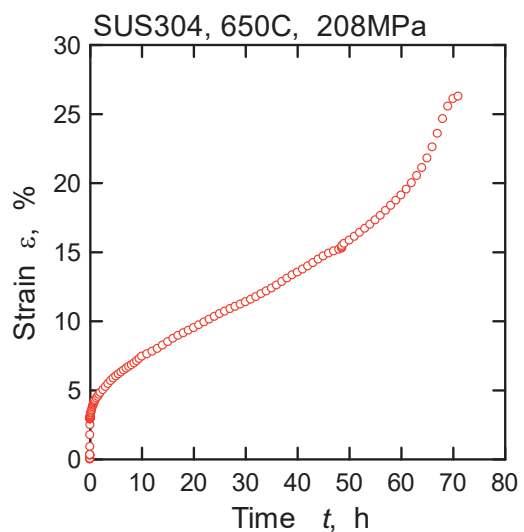

Fig. 11. Time - calculated strain curve for type 304 stainless steel at $923 \mathrm{~K}$.

\subsection{Biaxial creep testing}

Biaxial creep testing of type 304 stainless steel was also conducted at $943 \mathrm{~K}$ under $\lambda=1$ and Mises equivalent stress $\sigma_{\mathrm{eq}}=200 \mathrm{MPa}$. Testing temperature was set to $943 \mathrm{~K}$, which is higher temperature than conventional usage temperature of type 304 stainless steel, to accelerate the creep deformation. Because of the testing specimen used in this biaxial creep testing had been received some mechanical and thermal damage due to machine operation verification testing and heating furnace checking testing before this creep testing, creep deformation properties and rupture life may differ from these of virgin materials.

Figure 12 shows observed photograph of the miniature cruciform testing specimen at just before rupture. Four circle shaped marks were painted at edge of center gauge part to calculate $\mathrm{X}$-axis strain and $\mathrm{Y}$-axis strain separately. Many cracks at grain boundary are observed clearly by using the displacement measuring system.

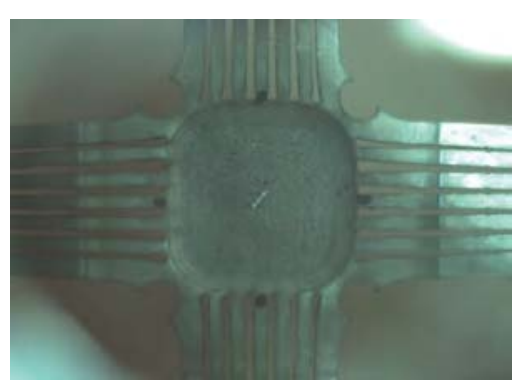

Fig. 12. Observed photograph of the miniature cruciform specimen at just before rupture.

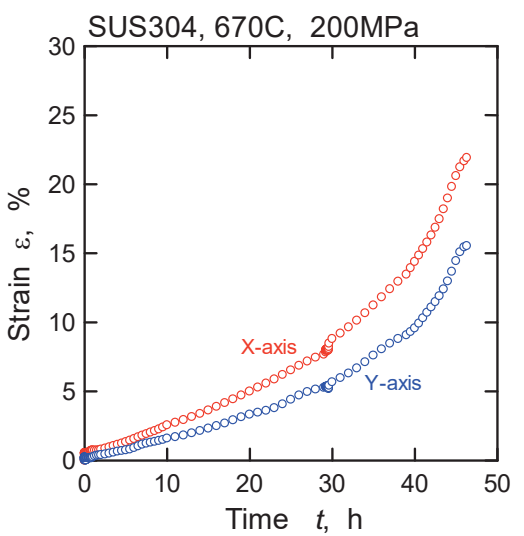

Fig. 13. Time - calculated strain curve for type 304 stainless steel.

Figure 13 is time-calculated strain curve for biaxial testing. Circle sharped symbol colored in red and blue indicate the calculated strain of Xaxis and $\mathrm{Y}$-axis, respectively. Both $\mathrm{X}$-axis and $\mathrm{Y}$-axis strain are obtained 
clearly by using the non-contact displacement measuring method, and the strain at rupture was $22 \%$ and $15 \%$ for $\mathrm{X}$-axis and $\mathrm{Y}$-axis, respectively. There is a small strain difference between $\mathrm{X}$-axis and $\mathrm{Y}$-axis even though the same load was applied to both $\mathrm{X}$-axis and $\mathrm{Y}$-axis directions. The detailed reason for the strain difference is still unknown, we need more sufficient data analysis and have to conduct creep testing with virgin specimen.

\section{Conclusions}

In this work, miniature cruciform specimen and testing machine are developed for creep testing. Non-contact displacement measuring method are also developed for creep testing. Conclusions of this work are as follows.

(1) The miniature cruciform specimen has $5 \mathrm{~mm} \times 5 \mathrm{~mm}$ square size and 1 $\mathrm{mm}$ thickness in center gauge part and $50 \mathrm{~mm} \times 50 \mathrm{~mm}$ in total width. Mises equivalent stress varies within a $\pm 5 \%$ at from center of the gauge part to $2.5 \mathrm{~mm}$.

(2) Calculated strain obtained by the non-contact displacement measuring method corresponds with the strain obtained by strain gauge and LVDT at room temperature and high temperature, respectively.

(3) The non-contact displacement measuring method can draw creep curve. The method also can investigate in-site creep deformation analysis.

We are still conducting creep testing with the miniature cruciform specimen and will explain the detail results at the conference.

This work was supported by JSPS KAKENHI Grant Number JP16K05973.

\section{References}

1. N. Hamada, M. Maruyama and H. Umeda, Transactions of the JSME 80, 1-12 (2014)

2. L. Niu, M. Kobayashi and H. Takaku, ISIJ International 42, 1156-1161 (2002)

3. N. Hiyoshi and Y. Iriyama, MATEC Web of Conferences 159 (2018)

4. S. Mukai, T. Takada, M. Sakane, M. Ohnami and T. Tsurui, J. Society of Materials Science, Japan 45, 559-565 (1996)

5. S. Zhang, T. Wakai, M. Sakane, Materials Science and Engineerig A 510-511, 110-114 (2009) 